\title{
Glioma-related seizures in relation to histopathological subtypes: a report from the glioma international case-control study
}

\author{
Shala G. Berntsson ${ }^{1} \cdot$ Ryan T. Merrell ${ }^{2} \cdot$ E. Susan Amirian ${ }^{3} \cdot$ Georgina N. Armstrong ${ }^{3} \cdot$ Daniel Lachance $^{4}$. \\ Anja Smits ${ }^{1,20} \cdot$ Renke Zhou $^{3,4}$. Daniel I. Jacobs ${ }^{3} \cdot$ Margaret R. Wrensch $^{5} \cdot$ Sara H. Olson $^{6}$. Dora II'yasova ${ }^{7}$. \\ Elizabeth B. Claus ${ }^{8}$. Jill S. Barnholtz-Sloan ${ }^{9}$. Joellen Schildkraut ${ }^{10}$. Siegal Sadetzki ${ }^{11,12}$. Christoffer Johansen ${ }^{13,14}$. \\ Richard S. Houlston ${ }^{15,16} \cdot$ Robert B. Jenkins ${ }^{16}$. Jonine L. Bernstein ${ }^{6} \cdot$ Rose Lai $^{17}$. Sanjay Shete ${ }^{18}$. \\ Christopher I. Amos ${ }^{3} \cdot$ Melissa L. Bondy ${ }^{3}$ Beatrice S. Melin ${ }^{19}$
}

Received: 12 February 2018 / Revised: 31 March 2018 / Accepted: 2 April 2018 / Published online: 23 April 2018

(c) The Author(s) 2018

\begin{abstract}
Background The purpose of this study was to evaluate the distribution of glioma-related seizures and seizure control at the time of tumor diagnosis with respect to tumor histologic subtypes, tumor treatment and patient characteristics, and to compare seizure history preceding tumor diagnosis (or study enrollment) between glioma patients and healthy controls.

Methods The Glioma International Case Control study (GICC) risk factor questionnaire collected information on demographics, past medical/medication history, and occupational history. Cases from eight centers were also asked detailed questions on seizures in relation to glioma diagnosis; cases $(n=4533)$ and controls $(n=4171)$ were also asked about seizures less than 2 years from diagnosis and previous seizure history more than 2 years prior to tumor diagnosis, including childhood seizures. Results Low-grade gliomas (LGGs), particularly oligodendrogliomas/oligoastrocytomas, had the highest proportion of glioma-related seizures. Patients with low-grade astrocytoma demonstrated the most medically refractory seizures. A total of $83 \%$ of patients were using only one antiepileptic drug (AED), which was levetiracetam in $71 \%$ of cases. Gross total resection was strongly associated with reduced seizure frequency $(p<0.009)$. No significant difference was found between glioma cases and controls in terms of seizure occurring more than 2 years before diagnosis or during childhood.

Conclusions Our study showed that glioma-related seizures were most common in low-grade gliomas. Gross total resection was associated with lower seizure frequency. Additionally, having a history of childhood seizures is not a risk factor $* * *$ for developing glioma-related seizures or glioma.
\end{abstract}

Keywords Observational study (cohort, case-control) $\cdot$ Epileptic seizures $\cdot$ Primary brain tumor $\cdot$ Glioma-related seizures

\section{Introduction}

Epileptic seizures are among the most common presenting symptom in patients with glioma [1]. Glioma-related seizures may occur at different time points during the course of a patients' illness, and can present either as focal seizures with or without impairment of consciousness or evolving to

Shala G. Berntsson and Ryan T. Merrell contributed equally to this work.

Melissa L. Bondy and Beatrice S. Melin co-last authors.

Shala G. Berntsson

shala.berntsson@neuro.uu.se

Extended author information available on the last page of the article bilateral, convulsive seizures [2, 3]. The etiology of gliomarelated seizures is complex and not completely understood, but patients diagnosed with low-grade gliomas (LGGs) have a higher risk for developing medically refractory epileptic seizures than those with higher tumor grades (i.e., anaplastic glioma and glioblastoma) [1]. An imbalance between the excessive release of neuroexcitatory glutamate and impaired GABAergic inhibition in the microenvironment surrounding the tumor has been suggested as one possible mechanism in glioma-related seizure development [4-7].

Treatment with antiepileptic drugs (AEDs) is critical for care of glioma patients, and good seizure control is an essential factor for improved quality of life. First-generation AEDs, such as phenytoin, carbamazepine, and valproic acid, have largely been replaced by newer AEDs, such as 
levetiracetam, lacosamide, and lamotrigine [8]. These newer drugs are characterized by lower hepatic enzyme inducing properties, fewer drug-drug interactions, and more favorable tolerability profiles.

The goal of the current study was threefold: (1) evaluate the distribution of glioma-related seizures at the time of tumor diagnosis with respect to tumor- and patient-related characteristics; (2) assess epileptic seizure frequency in relation to AED therapy and glioma treatment (surgery and radiotherapy); (3) compare seizure history preceding tumor diagnosis for cases and study enrollment for controls.

\section{Materials and methods}

\section{Study population}

The Glioma International Case-Control study (GICC) recruited 4533 cases and 4171 controls from 14 centers in the US, Europe, and Israel. Details on the GICC study population and methodology have previously been published [9]. Cases were between 18 and 80 years old at diagnosis, were histologically confirmed, and were recruited within 1 year of diagnosis of glioma.

Supratentorial and infratentorial gliomas were classified according to the $2007 \mathrm{WHO}$ classification of brain tumors as follows: fibrillary astrocytoma (9420/3), protoplasmic astrocytoma (9410/3), gemistocytic astrocytoma (9411/3), oligodendroglioma (9450/3), oligoastrocytoma (9382/3), anaplastic astrocytoma (9401/3), anaplastic oligodendroglioma (9451/3), anaplastic oligoastrocytoma (9382/3), gliosarcoma (9442/3), or glioblastoma (9440/3) [10]. WHO grade I gliomas, which are usually low-proliferation, oftencurable tumors were not included in this study. Thus, lowgrade glioma (LGG) refers to WHO grade II tumors, including the following subtypes: astrocytoma, oligodendroglioma, and oligoastrocytoma. Anaplastic glioma refers to WHO grade III gliomas, including astrocytomas, oligodendrogliomas, and oligoastrocytomas, whereas glioblastoma refers to WHO grade IV glioma, the most malignant type included in this study. A pathology review was performed on participants in the first year of the study and demonstrated good concordance of the histopathology [9].

All recruitment sites received Institutional Review Board (IRB) or ethical board approval to conduct the study, and informed consent was obtained from participants.

\section{Data collection}

Every site administered a common study protocol and questionnaire (full or abbreviated version), and data were stored in a centralized web-based database. The questionnaire was only administered at one time point. The GICC risk factor questionnaire collected information on demographic characteristics, past medical/medication history, and occupational history. Questionnaires were administered in person and/ or by phone, or through mailed self-administered forms. Eight sites administered the full version of the questionnaire (The University of Texas MD Anderson Cancer Center, Danish Cancer Society Research Centre, Memorial Sloan Kettering Cancer Center, Brigham and Women's Hospital, Case Western Reserve University, Mayo Clinic, NorthShore University HealthSystem and Umeå University). Some sites (Duke University, University of California, San Francisco, Institute of Cancer Research, UK, Gertner Institute, Israel, Columbia University, and University of Southern California) opted not to collect detailed seizure history [9]. All cases were asked if they had ever been diagnosed with seizures, convulsions, or epilepsy and the age at which they were diagnosed. In addition, at the sites that administered the full questionnaire, the glioma cases were asked if they had childhood seizures (febrile or not), when their epilepsy was diagnosed in relation to their brain tumor, if they had ever had an impairment of consciousness during a seizure, or bilateral convulsive epileptic seizures (grand mal), how many seizures they had had in the last 2 months, and if they were currently taking AED, and if so, what type of AED. For our analysis, we defined glioma-related seizures as seizures that began $\leq 2$ years before diagnosis.

\section{Statistical analyses}

The overall GICC analysis plan and a detailed table of demographics by study site are described elsewhere [9]. The main parameters of interest were history of seizures, the relative timing of the first epileptic seizure in relation to glioma diagnosis, age at epilepsy diagnosis, and epileptic seizure characteristics including impairment or loss of consciousness evolving to bilateral convulsive seizures, AED use, and seizure control (defined as recurrent epileptic seizures in spite of AED use and the subsequent frequency of seizures) during the last 2 months before the interview.

Case-only analyses were conducted using multinomial models. For the case-control analyses, we calculated adjusted odds ratios (ORs), along with their corresponding 95\% Wald confidence intervals (CIs), using unconditional logistic regression. We decided a priori to control for age and sex, glioma subtype, and study site in all multivariable models. Despite our large sample size, some strata were sparse within the histologic subtypes (Table 2). As a result, we pooled the data from all sites rather than conducting meta-analysis. While we acknowledge that pooling has limitations because of the inter-site heterogeneity present in our consortium, the pooled analyses are exploratory, and therefore, allowed us to evaluate whether there might be some implication of an effect that should be examined in future 
studies of larger subgroups. Sensitivity analyses included running models with and without proxy responses ( $\sim 8 \%$ of the cases).

\section{Results}

Descriptive statistics for glioma cases (overall and by histologic subtypes) and controls are presented in Table 1. Median time interval from diagnosis to questionnaire was 3.2 months for GBM, 4.6 months for anaplastic astrocytoma
(Table 5). Glioma occurred more frequently in males than females ( 59 vs. $41 \%$ ), both in the entire sample and by tumor subtypes. Patients with LGG were younger at diagnosis (30-39 years) than patients with anaplastic glioma (40-59 years) or glioblastoma (50-69 years). Approximately, onethird of all glioma cases (28.5\%) reported diagnosis of seizures, convulsions, or epilepsy (Table 1). Among cases reporting the relative timing of their first seizures $(n=1376)$, there were cases who, reported uncertainty about the time interval $(n=112)$, leaving a total of 1264 cases for the analysis. Epileptic seizures occurred most commonly within 2 years prior to glioma diagnosis $(n=1158)$ (Table 1).

Table 1 Selected population characteristics from the glioma international case-control study by case-control status and glioma histology group

\begin{tabular}{|c|c|c|c|c|c|c|c|c|}
\hline & Glioma cases & Controls & Glioblastoma & $\begin{array}{l}\text { Anaplastic } \\
\text { astrocytoma }\end{array}$ & $\begin{array}{l}\text { Anaplastic } \\
\text { oligodendro- } \\
\text { glioma/oli- } \\
\text { goastrocytoma }\end{array}$ & $\begin{array}{l}\text { LGG Astrocy- } \\
\text { toma }\end{array}$ & $\begin{array}{l}\text { LGG Oligo- } \\
\text { dendroglioma/ } \\
\text { oligoastrocy- } \\
\text { toma }\end{array}$ & Other \\
\hline & $N(\%)$ & $N(\%)$ & $N(\%)$ & $N(\%)$ & $N(\%)$ & $N(\%)$ & $N(\%)$ & $N(\%)$ \\
\hline \multicolumn{9}{|l|}{ Sex } \\
\hline Male & $2679(59.1)$ & $2351(56.37)$ & $1727(62.3)$ & $294(55.58)$ & $142(51.64)$ & $199(53.35)$ & $241(53.44)$ & $76(57.14)$ \\
\hline Female & $1854(40.9)$ & $1820(43.63)$ & $1045(37.7)$ & $235(44.42)$ & $133(48.36)$ & $174(46.65)$ & $210(46.56)$ & $57(42.86)$ \\
\hline \multicolumn{9}{|c|}{ Age at diagnosis/enrollment } \\
\hline $18-29$ years & 308 (6.79) & $294(7.05)$ & $62(2.24)$ & $68(12.85)$ & $25(9.09)$ & $65(17.43)$ & $70(15.52)$ & $18(13.53)$ \\
\hline 30-39 years & $521(11.49)$ & $473(11.34)$ & $108(3.9)$ & $115(21.74)$ & $54(19.64)$ & $99(26.54)$ & $122(27.05)$ & $23(17.29)$ \\
\hline $40-49$ years & $813(17.94)$ & $680(16.3)$ & $417(15.04)$ & $110(20.79)$ & $63(22.91)$ & $89(23.86)$ & $114(25.28)$ & $20(15.04)$ \\
\hline $50-59$ years & $1150(25.3)$ & $1079(25.87)$ & 795 (28.68) & $90(17.01)$ & $64(23.27)$ & $67(17.96)$ & $98(21.73)$ & $36(27.07)$ \\
\hline $60-69$ years & $1239(27.3)$ & $1098(26.32)$ & 993 (35.82) & 94 (17.77) & $52(18.91)$ & $40(10.72)$ & $37(8.2)$ & $23(17.29)$ \\
\hline $70-80$ years & $502(11.07)$ & $547(13.11)$ & 397 (14.32) & $52(9.83)$ & $17(6.18)$ & $13(3.49)$ & $10(2.22)$ & $13(9.77)$ \\
\hline \multicolumn{9}{|l|}{ Seizure history ${ }^{\mathrm{a}}$} \\
\hline $\begin{array}{l}\text { Glioma-related } \\
\text { seizures (sei- } \\
\text { zures } \leq 2 \text { years } \\
\text { of diagnosis) }\end{array}$ & 1158 (28.5) & - & 527 (21.11) & 186 (39.74) & $84(36.68)$ & $150(43.35)$ & $188(45.30)$ & $23(19.83)$ \\
\hline $\begin{array}{l}\text { Non-glioma- } \\
\text { related seizures } \\
\text { (seizure } \\
\text { initiation } \\
\text { started }>2 \text { years } \\
\text { before diagnosis }\end{array}$ & $106(2.60)$ & - & $55(8.86)$ & $15(6.79)$ & $2(2.15)$ & $13(7.22)$ & $14(6.20)$ & $7(20.00)$ \\
\hline $\begin{array}{l}\text { Cases with } \\
\text { seizures where } \\
\text { time of seizure } \\
\text { initiation not } \\
\text { reported }\end{array}$ & $112(2.75)$ & - & $39(6.28)$ & $20(9.05)$ & $7(7.53)$ & $17(9.44)$ & $24(10.62)$ & $5(14.29)$ \\
\hline No seizures & $2568(63.1)$ & - & 1792 (71.79) & 233 (49.79) & 130 (56. (77) & $157(45.38)$ & $179(43.13)$ & $77(66.38)$ \\
\hline Missing & $126(3.1)$ & - & $83(3.33)$ & $14(2.99)$ & $6(2.62)$ & $9(2.6)$ & $10(2.41)$ & $4(3.45)$ \\
\hline
\end{tabular}

$L G G$ low-grade glioma

${ }^{a}$ UK did not answer this section and was excluded. ORs adjusted for sex and age

and oligodendroglioma and finally 4.2 months for patients with low-grade gliomas.

3944 of the $4533(87 \%)$ glioma cases and 3244 of the $4171(78 \%)$ controls completed the full questionnaire
There was a significant difference in history of ever having been diagnosed with epileptic seizures (including seizure diagnoses within 2 years prior to tumor diagnosis) between patients with glioblastoma (26\%) and those with low-grade 
oligodendroglioma/oligoastrocytoma (56\%) or low-grade astrocytoma (53\%) (Table 2). Grade II oligodendroglioma/ oligoastrocytoma patients were 3 times more likely to have had a history of epileptic seizures compared to glioblastoma patients ( $\mathrm{OR}=3.03$; CI 2.41-3.82, $p<0.0001)$ (Table 2).

Patients with grade II oligodendroglioma/oligoastrocytoma, grade II astrocytoma, and anaplastic astrocytoma were more likely to have generalized epileptic seizures than cases with glioblastoma and anaplastic oligodendroglioma $(p<0.0001)$ (Table 2). There were a higher proportion of LGG patients who had recurrent epileptic seizures than cases with anaplastic glioma and glioblastoma, despite treatment with AEDs. Low-grade astrocytoma cases were about 1.6 times more likely to have recurrent epileptic seizures compared to glioblastoma cases $(\mathrm{OR}=1.55 ; 95 \% \mathrm{CI}$ $1.03-2.33 p=0.15$ ) (Table 2).

Overall, $83 \%$ of cases with epileptic seizures were prescribed one AED; $12 \%$ were on two AEDs; and 3\% used 3-5 AEDs. Levetiracetam was the AED of choice in $71 \%$ of cases (Table 3).

Treatment information in terms of type of surgery (gross total resection vs. subtotal resection/biopsy) and radiotherapy (yes or no) was only available in a subset of cases (23\%). Gross total resection (GTR) was strongly associated with reduced frequency of epileptic seizures; glioma cases who had GTR were $72 \%$ less likely to have reported $>10$ seizures during the 2 months immediately prior to the interview, compared with cases that underwent subtotal resection or biopsy $(n=255)(\mathrm{OR}=0.28$; CI $0.11-0.73, p<0.009)$. Radiotherapy, during first-line treatment, was not associated with epileptic seizure control $(p<0.85)$ (Table 4$)$.

Glioma cases were as likely as controls to experience febrile $(\mathrm{OR}=1.13$; 95\% CI $0.73-1.75, p=0.59)$ and nonfebrile seizures $(\mathrm{OR}=1.61$; 95\% CI $0.93-2.76, p=0.09)$ during childhood (Table 5).

\section{Discussion}

Our study is one of the largest studies to date of gliomarelated seizures in relation to proximity of diagnosis, glioma histology, and treatment by AEDs, as well as tumor treatment by resection and radiotherapy. Our results confirms a lower mean age at onset in patients with LGGs compared to anaplastic glioma and glioblastoma, as well as a higher rate of epileptic seizures as a presenting symptom, a phenomenon that has been well established in other large epidemiological studies [11-13]. We also observed a higher frequency of seizures among low-grade oligodendroglioma/oligoastrocytoma cases compared to glioblastoma cases, consistent with previous reports. Our data confirm the relatively long time interval that is needed for the development of tumorrelated seizures in the brain and the association between seizure risk and the growth rate of the tumor. Patients with LGGs, and particularly oligodendroglial tumors, are therefore, generally more prone to seizures than patients with high-grade gliomas $[3,14,15]$. The mechanisms behind seizure development in slow-growing tumors are different from high-grade tumors. Chronic deafferentation and disconnection of functionally isolated regions of cortex, causing a denervation hypersensitivity is connected to seizure risk in LGGs, whereas the direct effects of tissue damage in fast-growing high-grade gliomas by disturbed microvascularization and peritumoral ischemia are thought to be causative factors [16, 17].

We also found that patients with low-grade astrocytoma patients had significantly more recurrent seizures in spite of combined antiepileptic treatments. These differences in seizure control may reflect the differences in tumor locations of the glioma subtypes. Astrocytomas are more frequently associated with location in temporal or insular areas, while oligodendroglial tumors are more often located in frontal areas $[14,18]$.

Refractory seizures in patients with LGGs is a major concern in clinical neuro-oncology practice [19]. The epileptogenic zone of LGGs, especially in tumors located in temporal and paralimbic areas, involves not only the tumor itself but also extra-tumoral cortical areas, explaining the poor seizure control in 15-20\% of patients after gross total tumor resection. Improved postoperative seizure control was achieved in cases where the resection involved both the tumor and the epileptogenic zone surrounding the tumor [20-24].

Moreover, the treatment of glioma-related epilepsy with AED is complex. Cognitive side effects, interactions between AEDs and between AED treatment and chemotherapy are important aspects that need to be considered. Increased susceptibility to the cognitive side effects of AEDs was much more frequent than the side effects of radiotherapy in patients with LGGs [25]. Finally, the difficulties of obtaining good seizure control in spite of optimal AED and tumor treatment also illustrate the natural course of LGGs as a progressive and eventually fatal disease.

Our data demonstrate that patients with LGG, particularly low-grade astrocytoma, should be closely monitored for seizures.

Recently, a large multicenter French study provided detailed information on approximately 1500 LGGs, and identified male sex and tumor location in functional areas as independent predictors for tumor-related epileptic seizures [12]. The correlation between glioma-related seizures and male sex was not confirmed in the present study. In addition, among LGGs, the prevalence of self-reported glioma-related seizures was slightly lower in our study than in previous studies $[1,12,14,26]$. A potential reason is the possible poor recall of events. Patients may only 


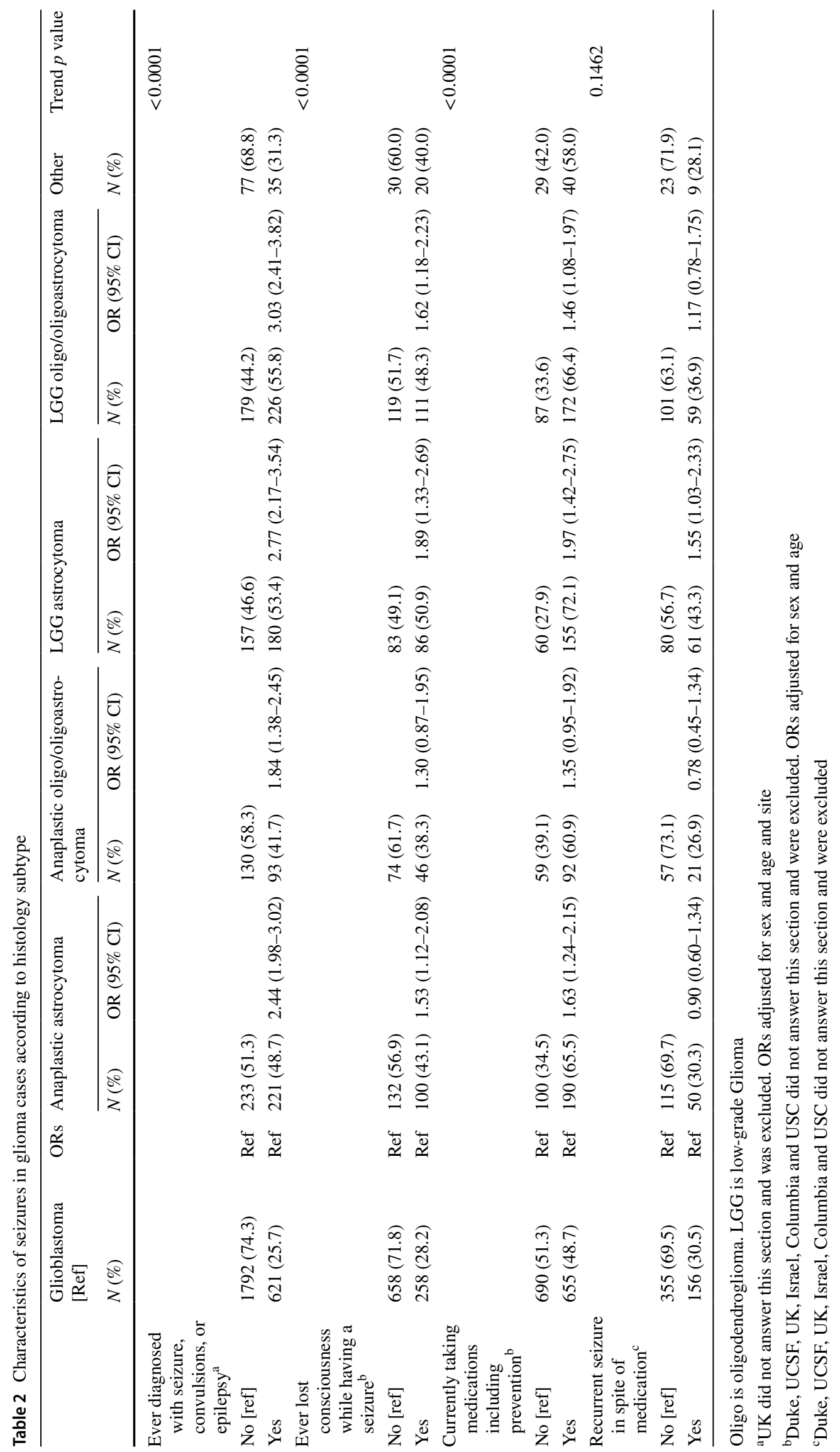


Table 3 Seizure information and use of medication for seizure in glioma cases) by glioma histology group

\begin{tabular}{|c|c|c|c|c|c|c|c|}
\hline & Glioblastoma $N(\%)$ & $\begin{array}{l}\text { Anaplastic } \\
\text { astrocytoma } \\
N(\%)\end{array}$ & $\begin{array}{l}\text { Anaplastic oligo/ } \\
\text { oligoastrocytoma } \\
N(\%)\end{array}$ & $\begin{array}{l}\mathrm{LGG} \\
\text { astrocytoma } \\
N(\%)\end{array}$ & $\begin{array}{l}\text { LGG oligo/oli- } \\
\text { goastrocytoma } \\
N(\%)\end{array}$ & Other $N(\%)$ & Total $N(\%)$ \\
\hline \multicolumn{8}{|c|}{ As a child ever had seizures with high fever ${ }^{b}$} \\
\hline Yes & $22(1.53)$ & $10(3.27)$ & $2(1.24)$ & $4(1.79)$ & $4(1.5)$ & $1(1.37)$ & $43(1.74)$ \\
\hline No & $1365(94.92)$ & $285(93.14)$ & $158(98.14)$ & $212(94.64)$ & $253(94.76)$ & $68(93.15)$ & $2341(94.82)$ \\
\hline Missing & $51(3.55)$ & $11(3.59)$ & $1(0.62)$ & $8(3.57)$ & $10(3.75)$ & $4(5.48)$ & $85(3.44)$ \\
\hline \multicolumn{8}{|c|}{$\begin{array}{l}\text { Has a child ever had } \\
\text { seizure not caused } \\
\text { by high fever }\end{array}$} \\
\hline Yes & $18(1.25)$ & $5(1.63)$ & 0 & $4(1.79)$ & $5(1.87)$ & $4(5.48)$ & $36(1.46)$ \\
\hline No & $1374(95.55)$ & $290(94.77)$ & $156(96.89)$ & $216(96.43)$ & $252(94.38)$ & $65(89.04)$ & $2353(95.3)$ \\
\hline Missing & $46(3.2)$ & $11(3.59)$ & $5(3.11)$ & 4 (1.79) & $10(3.75)$ & $4(5.48)$ & $80(3.24)$ \\
\hline \multicolumn{8}{|c|}{$\begin{array}{l}\text { Ever had a bilateral } \\
\text { convulsive seizure }^{\mathrm{b}}\end{array}$} \\
\hline Yes & $124(28.18)$ & $59(35.33)$ & $31(37.8)$ & $52(36.36)$ & $61(36.53)$ & 13 (41.94) & $340(33.01)$ \\
\hline No & $245(55.68)$ & $85(50.9)$ & $37(45.12)$ & $69(48.25)$ & $79(47.31)$ & 15 (48.39) & $530(51.46)$ \\
\hline Missing & $71(16.14)$ & $23(13.77)$ & $14(17.07)$ & $22(15.39)$ & 27 (16.17) & $3(9.68)$ & $160(15.54)$ \\
\hline \multicolumn{8}{|c|}{$\begin{array}{l}\text { No of seizure } \\
\text { medications }^{\mathrm{a}}\end{array}$} \\
\hline 1 & $339(85.18)$ & $126(80.77)$ & $68(89.47)$ & $104(77.61)$ & $120(79.47)$ & $23(88.46)$ & 780 (82.89) \\
\hline 2 & $44(11.06)$ & $23(14.74)$ & $5(6.58)$ & $21(15.67)$ & $20(13.25)$ & $3(11.54)$ & $116(12.33)$ \\
\hline 3 & $5(1.26)$ & $3(1.92)$ & $1(1.32)$ & $8(5.97)$ & $8(5.3)$ & 0 & $25(2.66)$ \\
\hline 4 & 0 & $1(0.64)$ & 0 & $1(0.75)$ & $1(0.66)$ & 0 & $3(0.32)$ \\
\hline 5 & $1(0.25)$ & 0 & 0 & 0 & 0 & 0 & $1(0.11)$ \\
\hline Missing & $9(2.26)$ & $3(1.92)$ & $2(2.63)$ & 0 & $2(1.32)$ & 0 & $16(1.7)$ \\
\hline \multicolumn{8}{|c|}{$\begin{array}{l}\text { Ever taken } \\
\text { levetiracetam }^{\mathrm{b}}\end{array}$} \\
\hline Yes & $301(75.63)$ & $112(71.79)$ & $49(64.47)$ & $90(67.16)$ & $98(64.9)$ & $18(69.23)$ & 668 (70.99) \\
\hline No & $97(24.37)$ & $44(28.21)$ & $27(35.53)$ & $44(32.84)$ & $53(35.1)$ & $8(30.77)$ & $273(29.01)$ \\
\hline
\end{tabular}

Oligo is oligodendroglioma, LGG is low-grade glioma

${ }^{a}$ MDA, Denmark, MSK, Brigham and Women, Case Western, Mayo, Northshore and Sweden provided this information

${ }^{\mathrm{b}}$ Duke, UCSF, UK, Israel, Columbia and USC did not ask these questions

report more dramatic seizure episodes, such as secondary generalized seizures, and due to cognitive decline, may fail to recall less severe focal seizures, such as left-hemispheric temporal lobe seizures. In our study, data were collected through self-reported questionnaires, as opposed to clinical observation or medical record abstraction, which could be one of the reasons for differences in the rates of epileptic seizures between the studies.

Furthermore, LGGs and anaplastic astrocytomas were more commonly associated with generalized seizures than glioblastoma. These findings support the existence of different epileptogenic pathways for LGG and high-grade gliomas $[17,24]$. From an epileptogenic point of view, this finding reinforces the general concept that slow-growing tumors have a lower epileptic threshold than fast-growing lesions [1].
Somatic isocitrate-dehydrogenase 1 (IDH1) mutations are common in LGGs, leading to the production of D-2 hydroxyglutarate, a metabolite that bears structural similarities to glutamate [27]. Thus, the IDH1 mutation in the tumor cells renders the tumor in a higher excitatory state and may be directly involved in the pathogenesis of tumor-related seizures in LGGs [28]. Routine testing of IDH1 mutational status was not performed at the time of our data collection. However, given that the frequency of IDH mutation in LGG approaches $80 \%$ and its possible role in epileptogenesis, a partial explanation for the observed higher frequency of epileptic seizures in LGGs could be due to IDH1 mutation status [29].

In this study, we only have data from time of study enrollment/diagnosis, and no follow-up data was collected. Glioma patients who presented with other tumor-related 
Table 4 Association between seizure frequency during the last 2 months and glioma case subtype

\begin{tabular}{|c|c|c|c|c|c|c|c|c|c|}
\hline & $\begin{array}{l}\text { Seizure free; } \\
\text { ref; } N(\%)\end{array}$ & $\begin{array}{l}1-5 \text { seizures } \\
N(\%)\end{array}$ & $\begin{array}{l}6-10 \text { seizures } \\
N(\%)\end{array}$ & $\begin{array}{l}>10 \text { seizures } \\
N(\%)\end{array}$ & Total $N$ & $\begin{array}{l}1-5 \text { seizures } \\
\text { OR }(95 \% \mathrm{CI})\end{array}$ & $\begin{array}{l}6-10 \text { seizures } \\
\text { OR }(95 \% \mathrm{CI})\end{array}$ & $\begin{array}{l}>10 \text { seizures } \\
\text { OR }(95 \% \mathrm{CI})\end{array}$ & $P$ value \\
\hline $\begin{array}{l}\text { Glioma sub- } \\
\text { type }\end{array}$ & & & & & & & & & 0.7461 \\
\hline $\begin{array}{l}\text { Glioblastoma } \\
\text { [ref] }\end{array}$ & $380(80.34)$ & $70(14.80)$ & $6(1.27)$ & $17(3.59)$ & 473 & 1.00 & 1.00 & 1.00 & \\
\hline $\begin{array}{l}\text { Anaplastic } \\
\text { oligo/oli- } \\
\text { goastrocy- } \\
\text { toma }\end{array}$ & $51(78.46)$ & $10(15.38)$ & $1(1.54)$ & $3(4.62)$ & 65 & $\begin{array}{l}0.95(0.45- \\
2.00)\end{array}$ & $\begin{array}{l}0.82(0.09- \\
7.48)\end{array}$ & $\begin{array}{l}1.14(0.31- \\
4.16)\end{array}$ & \\
\hline $\begin{array}{l}\text { Anaplastic } \\
\text { astrocytoma }\end{array}$ & $92(74.80)$ & $24(19.51)$ & $1(0.81)$ & $6(4.88)$ & 123 & $\begin{array}{l}1.24(0.72- \\
2.14)\end{array}$ & $\begin{array}{l}0.42(0.05- \\
3.87)\end{array}$ & $\begin{array}{l}1.22(0.45- \\
3.30)\end{array}$ & \\
\hline $\begin{array}{l}\text { LGG, astrocy- } \\
\text { toma }\end{array}$ & $65(70.65)$ & $13(14.13)$ & $3(3.26)$ & $11(11.96)$ & 92 & $\begin{array}{l}0.90(0.44- \\
1.85)\end{array}$ & $\begin{array}{l}1.86(0.36- \\
9.61)\end{array}$ & $\begin{array}{l}3.25(1.27- \\
8.29)\end{array}$ & \\
\hline $\begin{array}{l}\text { LGG, oligo/ } \\
\text { oligoastro- } \\
\text { cytoma }\end{array}$ & $87(72.50)$ & $23(19.17)$ & $3(2.50)$ & $7(5.83)$ & 120 & $\begin{array}{l}1.16(0.60- \\
2.23)\end{array}$ & $\begin{array}{l}1.35(0.23- \\
7.78)\end{array}$ & $\begin{array}{c}1.47(0.49- \\
4.39)\end{array}$ & \\
\hline Other & $22(78.57)$ & $3(10.71)$ & $1(3.57)$ & $2(7.14)$ & 28 & $\begin{array}{l}0.63(0.18- \\
2.22)\end{array}$ & $\begin{array}{c}1.93(0.19- \\
19.67)\end{array}$ & $\begin{array}{c}1.73(0.35- \\
8.40)\end{array}$ & \\
\hline Sex & & & & & & & & & 0.1522 \\
\hline Male [ref] & $411(78.74)$ & $84(16.09)$ & $4(0.77)$ & $23(4.41)$ & 522 & 1.00 & 1.00 & 1.00 & \\
\hline Female & $286(75.46)$ & $59(15.57)$ & $11(2.90)$ & $23(6.07)$ & 379 & $\begin{array}{l}0.96(0.67- \\
1.40)\end{array}$ & $\begin{array}{l}3.54(1.10- \\
11.39)\end{array}$ & $\begin{array}{l}1.31(0.71- \\
2.41)\end{array}$ & \\
\hline $\begin{array}{r}\text { Gross total } \\
\text { resection }\end{array}$ & & & & & & & & & 0.009 \\
\hline No [ref] & $481(74.46)$ & $111(17.18)$ & $13(2.01)$ & $41(6.35)$ & 646 & 1.00 & 1.00 & 1.00 & \\
\hline Yes & $216(84.71)$ & $32(12.55)$ & $2(0.78)$ & $5(1.96)$ & 255 & $\begin{array}{l}0.64(0.42- \\
0.99)\end{array}$ & $\begin{array}{l}0.36(0.08- \\
1.64)\end{array}$ & $\begin{array}{l}0.28(0.11- \\
0.73)\end{array}$ & \\
\hline Radiotherapy & & & & & & & & & 0.8558 \\
\hline No [ref] & $149(73.40)$ & $36(17.73)$ & 4 (1.97) & $14(6.90)$ & 203 & 1.00 & 1.00 & 1.00 & \\
\hline Yes & $548(78.51)$ & 107 (15.33) & $11(1.58)$ & $32(4.58)$ & 698 & $\begin{array}{l}0.83(0.50- \\
1.38)\end{array}$ & $\begin{array}{l}1.17(0.30- \\
4.64)\end{array}$ & $\begin{array}{l}0.82(0.38- \\
1.76)\end{array}$ & \\
\hline $\begin{array}{l}\text { Mean age } \\
\text { at glioma } \\
\text { diagnosis }\end{array}$ & 52.7 & 51.2 & 46.7 & 50.3 & & $\begin{array}{l}0.99(0.98- \\
1.01)\end{array}$ & $\begin{array}{l}0.98(0.94- \\
1.02)\end{array}$ & $\begin{array}{l}1.00(0.98- \\
1.03)\end{array}$ & 0.6138 \\
\hline Total & 697 & 143 & 15 & 46 & & & & & \\
\hline
\end{tabular}

Duke, UCSF, UK, Israel, Columbia, and USC did not take part in this section and were excluded. ORs adjusted for sex, age, gross total resection status (yes/no) and radiotherapy within 6 months (yes/no)

symptoms may not have an initial seizure until much later in course of their disease. Thus, these cases may not have been recognized as tumor-related seizures occurring postglioma diagnosis.

Levetiracetam was the most commonly used AED to treat patients in our study. Levetiracetam is a newer generation AED that has predictable pharmacokinetics with less concern for interaction with chemotherapeutic drugs, as is the case with the first-generation enzyme-inducing drugs, phenytoin and carbamazepine [30]. Newer generation AEDs such as levetiracetam do not induce or inhibit hepatic P450 enzymes. For this reason, the first-generation AEDs are often prohibited from being used in glioma patients who are enrolled in clinical trials. Although not more effective than first-generation AEDs, levetiracetam has been used as monotherapy with efficacy of $70-100 \%$ in gliomas, and is one of the drugs of choice for glioma-related seizures due to its favorable tolerability profile $[28,31,32]$. However, the standard of care for epileptic seizure prophylaxis may be different between the recruitment sites.

Although we only had data from a subset of the population, which may not be representative of the population as a whole, we observed a significant correlation between reduced seizure frequency and gross total resection, which is also consistent with previous studies where the extent of surgical resection is recognized as an independent predictor of controlled epileptic seizures after oncological treatment [14, 20, 33].

Based on the patient's status and specific characteristics, however, maximal surgery may have to be postponed, 
Table 5 Association between seizure diagnosis and casecontrol status $\begin{array}{lll}\text { Case } N(\%) \quad \text { Control } N(\%) & \begin{array}{l}\text { Multivariate models } \\ \text { ORs }(95 \% \mathrm{CI})\end{array}\end{array}$

\begin{tabular}{|c|c|c|c|c|}
\hline Ever diagnosed with seizure ${ }^{a}$ & & & & $<0.0001$ \\
\hline No [ref] & $2568(65.11)$ & $3141(93.82)$ & 1.00 & \\
\hline Yes & $1376(34.89)$ & $103(3.18)$ & $18.97(15.32-23.48)$ & \\
\hline $\begin{array}{l}\text { Non-glioma-related seizures (seizure } \\
\text { initiation started }>2 \text { years before } \\
\text { diagnosis) }\end{array}$ & & & & 0.221 \\
\hline No [ref] & $3838(97.31)$ & $3141(96.82)$ & 1.00 & \\
\hline Yes & $106(2.69)$ & $103(3.18)$ & $0.93(0.69-1.24)$ & \\
\hline Febrile seizures as a child ${ }^{\mathrm{b}}$ & & & & 0.5944 \\
\hline No [ref] & $2341(98.20)$ & $2413(98.29)$ & 1.00 & \\
\hline Yes & $43(1.80)$ & $42(1.71)$ & $1.13(0.73-1.75)$ & \\
\hline Non-febrile seizure as a child & & & & 0.0874 \\
\hline No [ref] & $2353(98.49)$ & $2474(99.08)$ & 1.00 & \\
\hline Yes & $36(1.51)$ & $23(0.92)$ & $1.61(0.93-2.76)$ & \\
\hline
\end{tabular}

${ }^{a}$ UK did not answer this section and was excluded. ORs adjusted for sex, glioma subtype, diagnosis age, and study sites

${ }^{\mathrm{b}}$ Duke, UCSF, UK, Israel, Columbia and USC did not answer this section and were excluded. Ref reference condition. Those with missing data were excluded from OR calculations particularly if the mass is situated in the eloquent areas of the brain.

Oncological treatment of the tumor is essential for glioma-related seizure control, and previous studies have reported improved seizure control in patients with LGGs after radiotherapy [34-36]. Moreover, two series of patients with low-grade gliomas have shown a significant lower seizure frequency following interstitial brachytherapy $[37,38]$.

However, we were not able to confirm this in our study, most likely because the interviews were conducted soon after the patient's diagnosis (median 3.6 months postdiagnosis), when improvement of seizure control by radiotherapy may not yet be achieved.

There was no significant difference in the incidence of epileptic seizures $>2$ years before diagnosis or in the history of seizures during childhood between cases and controls. A causal relationship between increased glioma risk and a history of epilepsy and/or exposure to AEDs long before brain tumor diagnosis has not been established [40-42]. Our study does not show that childhood seizures are risk factors for glioma-related seizures.

\section{Limitations of the study}

This study was a retrospective analysis of the GICC epidemiological study and an extensive medical chart review was not part of the analysis. One limitation common to all case-control studies is the potential for recall bias; although in this study, it is more likely that cases under-reported seizures due to poor memory related to cognitive impairment. We also acknowledge that grouping data from different centers that may have different standards of care may introduce a potential bias when interpreting the results. Furthermore, the results are based entirely on a one-time questionnaire completion and some centers opted out of full questionnaire completion. Another limitation of our study is related to the lack of information on the exact location of the tumor and volume estimates at surgery, variables that have been associated with seizure risk and control in gliomas [12, 24]. Additionally, a significant limitation is that we did not have access to detailed oncological treatment data, as the primary aim of the GICC was to analyze potential epidemiological associations and gene-environment interactions. In addition to what has been reported for the effects of radiotherapy on seizure control, prior studies have found positive effects of chemotherapy on epileptic seizure control. Our study was not primarily aimed at looking at these clinical factors, so we have limited data on treatment-related variables with the possibility of potential bias in the reported conclusions.

Our cases were diagnosed prior to the 2016 WHO classification so they are not classified with IDH mutation and $1 \mathrm{p} / 19 \mathrm{q}$ co-deletion status [43]. Future studies within the consortium will determine if there are genes that may lead to increased susceptibility to glioma-related seizures.

\section{Conclusion}

In conclusion, our large case series demonstrates a pattern of epileptic seizure prevalence and seizure control in patients with gliomas that confirms previous reports. Our study also 
confirms the strong association between epileptic seizures and slowly growing tumors. No relationship was found between a history of febrile seizures and glioma-related epileptic seizures, suggesting that remote seizure may not be a risk factor for developing glioma-related seizures or glioma.

Acknowledgements This work was supported by Grants from the NIH, Bethesda, MD:R01CA139020 (to M.L. Bondy), R01CA52689, P50CA97257 (to M.R. Wrensch). All authors received support from R01CA139020 (to M.L. Bondy). Additional support was provided by the McNair Medical Institute and the Population Sciences Biorepository at Baylor College of Medicine (P30CA125123).

Author contributions SGB: study concept, drafting manuscript, revising manuscript, accepts responsibility for conduct of research and final approval; RTM: study concept, drafting manuscript, revising manuscript, accepts responsibility for conduct of research and final approval; DL: study concept, drafting manuscript, revising manuscript, accepts responsibility for conduct of research and final approval; AS: study concept, revising manuscript, accepts responsibility for conduct of research and final approval; RZ: analysis and interpretation of data, drafting statistical analysis section, revision of manuscript, final approval; ESA: analysis and interpretation of data, drafting statistical analysis section, revision of manuscript, final approval; GNA: analysis and interpretation of data, revision of manuscript, final approval; MRW: data collection and revising manuscript; SHO: data collection and revising manuscript; DI: data collection and revising manuscript; EBC: data collection and revising manuscript; JSBS: data collection and revising manuscript; JS: data collection and revising manuscript; SS: data collection and revising manuscript; $\mathrm{CJ}$ : data collection and revising manuscript; RSH: data collection and revising manuscript; RBJ: data collection and revising manuscript; JLB: data collection and revising manuscript; RL: data collection and revising manuscript; SS: data collection and revising manuscript; CIA: study concept, revising manuscript; MLB: study concept, drafting manuscript, revising manuscript, accepts responsibility for conduct of research and final approval; BSM: study concept, collecting data, drafting manuscript, revising manuscript, accepts responsibility for conduct of research and final approval

\section{Compliance with ethical standards}

Funding This work was supported by Grants from the NIH, Bethesda, MD:R01CA139020 (to M.L. Bondy), R01CA52689, P50CA97257 (to M.R. Wrensch). All authors received support from R01CA139020 (to M.L. Bondy). Additional support was provided by the McNair Medical Institute and the Population Sciences Biorepository at Baylor College of Medicine (P30CA125123).

Conflicts of interest The authors declare no competing financial interests.

Informed consent Written informed consent was obtained from each subject or from his or her guardian. Approval from local institutional review boards was received at each Gliogene participating institution. This study was conducted in accordance with the Declaration of Helsinki.

Open Access This article is distributed under the terms of the Creative Commons Attribution 4.0 International License (http://creativeco mmons.org/licenses/by/4.0/), which permits unrestricted use, distribution, and reproduction in any medium, provided you give appropriate credit to the original author(s) and the source, provide a link to the Creative Commons license, and indicate if changes were made.

\section{References}

1. van Breemen MS, Wilms EB, Vecht CJ (2007) Epilepsy in patients with brain tumours: epidemiology, mechanisms, and management. Lancet Neurol 6(5):421-430

2. Berg AT, Berkovic SF, Brodie MJ, Buchhalter J, Cross JH, van Emde Boas W, Engel J, French J, Glauser TA, Mathern GW et al (2010) Revised terminology and concepts for organization of seizures and epilepsies: report of the ILAE Commission on Classification and Terminology, 2005-2009. Epilepsia 51(4):676-685

3. Ruda R, Trevisan E, Soffietti R (2010) Epilepsy and brain tumors. Curr Opin Oncol 22(6):611-620

4. Campbell SL, Robel S, Cuddapah VA, Robert S, Buckingham SC, Kahle KT, Sontheimer H (2015) GABAergic disinhibition and impaired $\mathrm{KCC} 2$ cotransporter activity underlie tumor-associated epilepsy. Glia 63(1):23-36

5. Mao XY, Tokay T, Zhou HH, Jin WL (2016) Long-range and short-range tumor-stroma networks synergistically contribute to tumor-associated epilepsy. Oncotarget 7(22):33451-33460

6. Nelp TB, McGovern RA, McKhann GM 2nd (2014) Why glioma patients seize: adding more pathological GABA to the glutamate hypothesis. Neurosurgery 75(6):N10-N11

7. Pallud J, Capelle L, Huberfeld G (2013) Tumoral epileptogenicity: how does it happen? Epilepsia 54(Suppl 9):30-34

8. Ruda R, Soffietti R (2015) What is new in the management of epilepsy in gliomas? Curr Treat Options Neurol 17(6):351

9. Amirian ES, Armstrong GN, Zhou R, Lau CC, Claus EB, Barnholtz-Sloan JS, Il'yasova D, Schildkraut J, Ali-Osman F, Sadetzki $\mathrm{S}$ et al (2016) The glioma international case-control study: a report from the Genetic Epidemiology of Glioma International Consortium. Am J Epidemiol 183(2):85-91

10. Louis DN, Ohgaki H, Wiestler OD, Cavenee WK, Burger PC, Jouvet A, Scheithauer BW, Kleihues P (2007) The 2007 WHO classification of tumours of the central nervous system. Acta Neuropathol 114(2):97-109

11. Ohgaki H, Kleihues P (2005) Population-based studies on incidence, survival rates, and genetic alterations in astrocytic and oligodendroglial gliomas. J Neuropathol Exp Neurol 64(6):479-489

12. Pallud J, Audureau E, Blonski M, Sanai N, Bauchet L, Fontaine D, Mandonnet E, Dezamis E, Psimaras D, Guyotat J et al (2014) Epileptic seizures in diffuse low-grade gliomas in adults. Brain 137(Pt 2):449-462

13. Wrensch M, Minn Y, Chew T, Bondy M, Berger MS (2002) Epidemiology of primary brain tumors: current concepts and review of the literature. Neuro Oncol 4(4):278-299

14. Chang EF, Potts MB, Keles GE, Lamborn KR, Chang SM, Barbaro NM, Berger MS (2008) Seizure characteristics and control following resection in 332 patients with low-grade gliomas. J Neurosurg 108(2):227-235

15. Lote K, Stenwig AE, Skullerud K, Hirschberg H (1998) Prevalence and prognostic significance of epilepsy in patients with gliomas. Eur J Cancer 34(1):98-102

16. Beaumont A, Whittle IR (2000) The pathogenesis of tumour associated epilepsy. Acta Neurochir (Wien) 142(1):1-15

17. Schaller B, Ruegg SJ (2003) Brain tumor and seizures: pathophysiology and its implications for treatment revisited. Epilepsia 44(9):1223-1232

18. Lee JW, Wen PY, Hurwitz S, Black P, Kesari S, Drappatz J, Golby AJ, Wells WM 3rd, Warfield SK, Kikinis R et al (2010) 
Morphological characteristics of brain tumors causing seizures. Arch Neurol 67(3):336-342

19. Loscher W, Potschka H (2002) Role of multidrug transporters in pharmacoresistance to antiepileptic drugs. J Pharmacol Exp Therapeutics 301(1):7-14

20. Englot DJ, Berger MS, Barbaro NM, Chang EF (2011) Predictors of seizure freedom after resection of supratentorial low-grade gliomas. A review. J Neurosurg 115(2):240-244

21. Ghareeb F, Duffau H (2012) Intractable epilepsy in paralimbic Word Health Organization Grade II gliomas: should the hippocampus be resected when not invaded by the tumor? J Neurosurg 116(6):1226-1234

22. Lombardi D, Marsh R, de Tribolet N (1997) Low grade glioma in intractable epilepsy: lesionectomy versus epilepsy surgery. Acta Neurochir Suppl 68:70-74

23. Ruda R, Bello L, Duffau H, Soffietti R (2012) Seizures in lowgrade gliomas: natural history, pathogenesis, and outcome after treatments. Neuro Oncol 14(Suppl 4):iv55-64

24. Smits A, Duffau H (2011) Seizures and the natural history of World Health Organization grade II gliomas: a review. Neurosurgery 68(5):1326-1333

25. Klein M, Heimans JJ, Aaronson NK, van der Ploeg HM, Grit J, Muller M, Postma TJ, Mooij JJ, Boerman RH, Beute GN et al (2002) Effect of radiotherapy and other treatment-related factors on mid-term to long-term cognitive sequelae in low-grade gliomas: a comparative study. Lancet 360(9343):1361-1368

26. Sherman JH, Moldovan K, Yeoh HK, Starke RM, Pouratian N, Shaffrey ME, Schiff D (2011) Impact of temozolomide chemotherapy on seizure frequency in patients with low-grade gliomas. J Neurosurg 114(6):1617-1621

27. Liubinas SV, D'Abaco GM, Moffat BM, Gonzales M, Feleppa F, Nowell CJ, Gorelik A, Drummond KJ, O'Brien TJ, Kaye AH et al (2014) IDH1 mutation is associated with seizures and protoplasmic subtype in patients with low-grade gliomas. Epilepsia 55(9):1438-1443

28. Huberfeld G, Vecht CJ (2016) Seizures and gliomas-towards a single therapeutic approach. Nature Rev Neurol 12(4):204-216

29. Cancer Genome Atlas Research N, Brat DJ, Verhaak RG, Aldape KD, Yung WK, Salama SR, Cooper LA, Rheinbay E, Miller CR, Vitucci M et al (2015) Comprehensive, integrative genomic analysis of diffuse lower-grade gliomas. N Engl J Med 372(26):2481-2498

30. Glantz MJ, Cole BF, Forsyth PA, Recht LD, Wen PY, Chamberlain MC, Grossman SA, Cairncross JG (2000) Practice parameter: anticonvulsant prophylaxis in patients with newly diagnosed brain tumors. Report of the Quality Standards Subcommittee of the American Academy of Neurology. Neurology 54(10):1886-1893

31. Maschio M, Dinapoli L, Sperati F, Pace A, Fabi A, Vidiri A, Muti $P$ (2011) Levetiracetam monotherapy in patients with brain tumor-related epilepsy: seizure control, safety, and quality of life. J Neurooncol 104(1):205-214
32. Rosati A, Buttolo L, Stefini R, Todeschini A, Cenzato M, Padovani A (2010) Efficacy and safety of levetiracetam in patients with glioma: a clinical prospective study. Arch Neurol 67(3):343-346

33. Luyken C, Blumcke I, Fimmers R, Urbach H, Elger CE, Wiestler OD, Schramm J (2003) The spectrum of long-term epilepsyassociated tumors: long-term seizure and tumor outcome and neurosurgical aspects. Epilepsia 44(6):822-830

34. Ruda R, Magliola U, Bertero L, Trevisan E, Bosa C, Mantovani C, Ricardi U, Castiglione A, Monagheddu C, Soffietti R (2013) Seizure control following radiotherapy in patients with diffuse gliomas: a retrospective study. Neuro Oncol 15(12):1739-1749

35. van den Bent MJ, Afra D, de Witte O, Ben Hassel M, Schraub S, Hoang-Xuan K, Malmstrom PO, Collette L, Pierart M, Mirimanoff $\mathrm{R}$ et al (2005) Long-term efficacy of early versus delayed radiotherapy for low-grade astrocytoma and oligodendroglioma in adults: the EORTC 22845 randomised trial. Lancet 366(9490):985-990

36. Warnke PC, Berlis A, Weyerbrock A, Ostertag CB (1997) Significant reduction of seizure incidence and increase of benzodiazepine receptor density after interstitial radiosurgery in low-grade gliomas. Acta Neurochir Suppl 68:90-92

37. Rossi GF, Scerrati M, Roselli R (1985) Epileptogenic cerebral low-grade tumors: effect of interstitial stereotactic irradiation on seizures. Appl Neurophysiol 48(1-6):127-132

38. Scerrati M, Montemaggi P, Iacoangeli M, Roselli R, Rossi GF (1994) Interstitial brachytherapy for low-grade cerebral gliomas: analysis of results in a series of 36 cases. Acta Neurochir (Wien) 131(1-2):97-105

39. Rosenquist TA, Zaika E, Fernandes AS, Zharkov DO, Miller H, Grollman AP (2003) The novel DNA glycosylase, NEIL1, protects mammalian cells from radiation-mediated cell death. DNA Repair (Amst) 2(5):581-591

40. Kuijten RR, Strom SS, Rorke LB, Boesel CP, Buckley JD, Meadows AT, Bunin GR (1993) Family history of cancer and seizures in young children with brain tumors: a report from the Childrens Cancer Group (United States and Canada). Cancer Causes Control: CCC 4(5):455-464

41. Olsen JH, Boice JD Jr, Jensen JP, Fraumeni JF Jr (1989) Cancer among epileptic patients exposed to anticonvulsant drugs. J Natl Cancer Inst 81(10):803-808

42. Shirts SB, Annegers JF, Hauser WA, Kurland LT (1986) Cancer incidence in a cohort of patients with seizure disorders. J Natl Cancer Inst 77(1):83-87

43. Louis DN, Perry A, Reifenberger G, von Deimling A, FigarellaBranger D, Cavenee WK, Ohgaki H, Wiestler OD, Kleihues P, Ellison DW (2016) The 2016 World Health Organization classification of tumors of the central nervous system: a summary. Acta Neuropathol 131(6):803-820

\title{
Affiliations
}

\author{
Shala G. Berntsson ${ }^{1} \cdot$ Ryan T. Merrell ${ }^{2}$ - E. Susan Amirian ${ }^{3} \cdot$ Georgina N. Armstrong ${ }^{3} \cdot$ Daniel Lachance $^{4}$. \\ Anja Smits ${ }^{1,20} \cdot$ Renke Zhou $^{3,4}$. Daniel I. Jacobs ${ }^{3} \cdot$ Margaret R. Wrensch $^{5} \cdot$ Sara H. Olson $^{6}$. Dora II'yasova ${ }^{7}$. \\ Elizabeth B. Claus ${ }^{8}$. Jill S. Barnholtz-Sloan ${ }^{9}$. Joellen Schildkraut ${ }^{10}$. Siegal Sadetzki ${ }^{11,12}$. Christoffer Johansen ${ }^{13,14}$. \\ Richard S. Houlston ${ }^{15,16} \cdot$ Robert B. Jenkins ${ }^{16}$. Jonine L. Bernstein ${ }^{6} \cdot$ Rose Lai $^{17}$. Sanjay Shete ${ }^{18}$. \\ Christopher I. Amos ${ }^{3} \cdot$ Melissa L. Bondy ${ }^{3} \cdot$ Beatrice S. Melin ${ }^{19}$
}

1 Department of Neuroscience, Neurology, Uppsala University, 75185 Uppsala, Sweden
2 Department of Neurology, NorthShore University HealthSystem, Evanston, IL, USA 
3 Division of Medicine, Dan L. Duncan Cancer Center, Baylor College of Medicine, Houston, TX, USA

4 Department of Neurology, Mayo Clinic Comprehensive Cancer Center, Mayo Clinic, Rochester, MN, USA

5 Department of Neurological Surgery, University of California, San Francisco, San Francisco, CA, USA

6 Department of Epidemiology and Biostatistics, Memorial Sloan-Kettering Cancer Center, New York, NY, USA

7 Department of Epidemiology and Biostatistics, Georgia State University School of Public Health, Atlanta, Georgia

8 Department of Epidemiology and Public Health, Yale University School of Medicine, New Haven, CT, USA

9 Case Comprehensive Cancer Center, Case Western Reserve University School of Medicine, Cleveland, OH, USA

10 Department of Public Health Sciences, University of Virginia, Charlottesville, VA, USA

11 Cancer and Radiation Epidemiology Unit, Gertner Institute, Chaim Sheba Medical Center, Tel Hashomer, Israel

12 Sackler School of Medicine, Tel-Aviv University, Tel-Aviv, Israel
13 Institute of Cancer Epidemiology, Danish Cancer Society, Copenhagen, Denmark

14 Rigshospitalet, University of Copenhagen, Copenhagen, Denmark

15 Section of Cancer Genetics, Institute of Cancer Research, Sutton, London, Surrey, UK

16 Department of Laboratory Medicine and Pathology, Mayo Clinic Comprehensive Cancer Center, Mayo Clinic, Rochester, MN, USA

17 Departments of Neurology, Neurosurgery, and Preventive Medicine, The University of Southern California Keck School of Medicine, Los Angeles, CA, USA

18 Department of Epidemiology, The University of Texas MD Anderson Cancer Center, Houston, TX, USA

19 Department of Radiation Sciences Oncology, Umeå University, Umeå, Sweden

20 Department of Clinical Neuroscience, Institute of Neuroscience and Physiology, Sahlgrenska Academy, University of Gothenburg, Gothenburg, Sweden 